\title{
Public Health England's report on sugar reduction
}

\author{
Its list of actions is good; now we need priorities
}

\author{
Mike Rayner director, Peter Scarborough university research lecturer, Adam Briggs Wellcome Trust \\ research training fellow
}

British Heart Foundation Centre on Population Approaches for Non-Communicable Disease Prevention, Nuffield Department of Population Health, University of Oxford, Oxford, UK

Public Health England (PHE) has published its long awaited report on the evidence for sugar reduction. ${ }^{1}$ It sets out eight key levers that the government could use when formulating a programme to reduce the population's intake of free sugars (all sugars added to foods plus those naturally present in fruit juices, syrups, and honey).

There is much to applaud. PHE is often criticised for not being bold enough in its recommendations to government, taking a cautious approach to its interpretation of the evidence and what it should mean to policy makers. However, at least four of the eight levers may need some form of legislation, and the range of suggested interventions goes beyond simply nudging individuals through health education (box). The breadth of the review is a strength: diet is complex and there is no silver bullet. No single policy will reduce sugar intake, and reducing sugar consumption in itself will not solve the obesity epidemic. A multifaceted approach is needed.

However, the breadth of the report is also its biggest problem. The mixed methodological approach is clumsy, ranging from systematic reviews of the evidence underlying fiscal interventions and reducing opportunities for marketing, through to a specially commissioned analysis of Kantar Worldpanel data to assess the effectiveness of reducing price promotions. These reviews and analyses are then bundled together to come up with the eight levers, each apparently given equal status.

\section{Passing the buck}

Although there is some prioritisation within the list, the reason for it is not sufficiently explicit. The quality of evidence for the effectiveness of the different levers varies widely, as does their potential population impact. Rather than quantifying individual effects, PHE concludes that implementation of the eight levers would result in meaningful reductions in population sugar consumption. This is undoubtedly true but passes the buck to politicians as to what to do next. The government could use the report to justify the continuation of its failing responsibility $\mathrm{deal}^{2}$ (or something similar) with a focus on reformulating products and reducing portion sizes on a voluntary basis, completely ignoring potentially more effective policies requiring legislation.

If the effect on diet of the different levers were quantified, or even better, their cost effectiveness estimated, the subsequent ability to rank the interventions would leave the government far less room for justifying the implementation of some policies over others. Prioritising public health interventions in a systematic and rigorous way is complex. ${ }^{3}$ To give PHE its due, producing what it has in the time available is no mean feat, but why hasn't the National Institute for Health and Care Excellence (NICE) been involved?

\section{Beyond sugar}

The PHE review was commissioned by the Department of Health to consider sugar reduction in the light of a report on carbohydrates and health from the Scientific Advisory Committee on Nutrition (SACN). ${ }^{3}$ At the same time PHE is updating official food based dietary guidance through a review of the eatwell plate ${ }^{4}$ and the government is finalising its childhood obesity strategy. It is anomalous-but perhaps understandable in the light of the media furore around sugar over the past year-for PHE to be asked to focus its review on just one nutrient. The same SACN report that recommended the 5\% limit on sugar and provoked the PHE review also recommended a substantial increase in fibre intake to $30 \mathrm{~g} / \mathrm{day}$ from the 23-24 g/day previously recommended. ${ }^{5}$ There is no comprehensive review of how this new fibre target might be met.

We have a population obesity crisis whereby a quarter of all adults are obese, as are one in 10 children aged $4-5$ years. ${ }^{6}$ Diet is now the leading cause of ill health in England, greater even than smoking. ${ }^{7}$ Yes, sugar is important but so are saturated fat, salt, fibre, and fruit and vegetable intakes. The responsibility deal hasn't worked. Instead a comprehensive and far reaching evidence based approach to the promotion of healthier (and indeed environmentally sustainable) diets is needed. We know it needs to be multifaceted, supported by both legislation and public education. 
PHE has done what it has been asked to do, but that's all. It needed more resources and more time to produce something with greater scope and clearer recommendations. It has certainly advanced the debate about sugar and, in particular, the clear need for a sugary drinks tax. And alongside chef Jamie Oliver, Action on Sugar, and Sarah Wollaston (chair of the UK parliament's health committee) it has done much to highlight to the public the health implications of overconsuming sugar. But is this really the best that can be done to provide the government with a clear set of priorities for action to improve the nation's diets?

Competing interests: We have read and understood BMJ policy on declaration of interests and declare the following interests: MR and PS are currently undertaking work funded by Public Health England on revising the eatwell plate; MR is chair of Sustain and a trustee of the UK Health Forum, AB is a member of the UK Faculty of Public Health.
Provenance and peer review: Commissioned; not externally peer reviewed.

1 Public Health England. Sugar reduction: the evidence for action. 2015. www.gov.uk/ government/uploads/system/uploads/attachment_data/file/470179/Sugar_reduction_The _ evidence_for_action.pdf.

2 Knai C, Petticrew M, Durand MA, et al. Has a public-private partnership resulted in action on healthier diets in England? An analysis of the Public Health Responsibility Deal food pledges. Food Policy 2015;54:1-10.

3 Dobbs R, Sawers C, Thompson F, et al. Overcoming obesity: an initial economic analysis. McKinsey, 2014

4 NHS Choices. Eatwell plate. www.nhs.uk/Livewell/Goodfood/Pages/eatwell-plate.aspx. Scientific Advisory Committee on Nutrition. Carbohydrates and health. 2015. www.gov. uk/government/uploads/system/uploads/attachment_data/file/445503/SACN Carbohydrates_and_Health.pdf.

6 National Obesity Observatory. About obesity. 2015. www.noo.org.uk/NOO about obesity. Newton JN, Briggs ADM, Murray CJL, et al. Changes in health in England, with analysis by English regions and areas of deprivation, 1990-2013: a systematic analysis for the Global Burden of Disease Study 2013. Lancet 2015. Sep 14. [Epub ahead of print.]

Cite this as: BMJ 2015;351:h6095

๑) BMJ Publishing Group Ltd 2015 


\section{PHE's eight levers to reduce sugar intake ${ }^{1}$}

Reduce and rebalance the number and type of price promotions in all retail outlets, including supermarkets and convenience stores, and the out of home sector (restaurants, cafes, etc)

Significantly reduce opportunities to market and advertise high sugar food and drink products to children and adults across all media, including digital platforms and through sponsorship

Set clear definitions for high sugar foods. Currently the only regulatory framework for doing this is the Ofcom nutrient profiling model, which would benefit from being reviewed and strengthened

Introduce a broad, structured, and transparently monitored programme of gradual sugar reduction in everyday food and drink products, combined with reductions in portion size

Introduce a price increase of a minimum of $10-20 \%$ on high sugar products through the use of a tax or levy, such as on full sugar soft drinks

Adopt, implement, and monitor the government buying standards for food and catering services across the public sector, including national and local government and the NHS to ensure provision and sale of healthier food and drinks in hospitals, leisure centres, etc Ensure that accredited training in diet and health is routinely delivered to all of those who have opportunities to influence food choices in the catering, fitness, and leisure sectors and others within local authorities

Continue to raise awareness of concerns around sugar levels in the diet to the public as well as to health professionals, employers, the food industry, etc; encourage action to reduce intakes and provide practical steps to help people lower their and their families' sugar intake 